\title{
Sobre as possibilidades de efetivação das cooperativas no cotidiano: uma aproximação construcionista
}

\author{
Roberto Minoru Ide \\ Pontifícia Universidade Católica de São Paulo
}

\begin{abstract}
O texto a seguir constitui uma resposta, dentre outras possíveis, para a questão feita por Paul Singer (1998) sobre os motivos que levam uma cooperativa a se degenerar ou não. A metodologia adotada segue os pressupostos construcionistas, que concebem o conhecimento como sendo intersubjetivo e histórico e que, portanto, negam toda essência ou verdade a priori. Assim, ao constatar que existem na historiografia referente ao tema outras noções de cooperativismo, além da organizativa, como as que se referem à questão, denominada por nós, de lugar ou com a questão da doutrina cooperativa, a discussão sobre as possibilidades da efetivação autogestionária de uma cooperativa toma como eixo central a temática do lugar como concebido por Peter Spink (2000): lugar das lutas diárias que agrupamentos realizam para sua sobrevivência.
\end{abstract}

Palavras-chave: Cooperativas, História do cooperativismo, Construcionismo social, Autogestão, Economia solidária.

On the possibilities of making effective cooperatives in every day life: a constructionist approach

The following text is an answer, among other possible ones, to the question made by Paul Singer (1998) about the reasons that lead or not to the degeneration of a cooperative. The methodology used follows the presuppositions of the constructionists who imagine knowledge as being inter-subjective and historical and that, therefore, deny all essence or truth a priori. Thus, when we verified that there is, in the historiography related to the subject, other notions of cooperativism, beyond of organizational notion, such as the ones that refer to the question, denominated by us the place, or to the question of the cooperative doctrine, the discussion about the possibilities of creating an effective self-managed cooperative takes as its central axis the thematics of the place as conceived by Peter Spink (2000): place of the daily fights that groups go through to survive.

Keywords: Cooperatives, History of cooperativism, Social constructionism, Self-management, Solidary economy.

\section{Introdução}

$\mathrm{D}$ urante a pesquisa de mestrado (Ide, 2004) ${ }^{1}$, pode-se verificar, na cidade de São Paulo, que existem duas tendências cooperativistas cujas linhas de argumentação acerca do cooperativismo não se confluem: os tradicionalistas e a economia solidária.

Como verificado, essa diferenciação ocorre por pertencerem a diferentes contextos de diálogos, que se transformaram de maneira diferenciada entre os períodos analisados: enquanto os atuais tradicionalistas brasileiros dialogam de forma discordante com os antigos intelectuais da Aliança Cooperativa Internacional ${ }^{2}$ (ACI), instituição fundada em 1895 e sediada em Londres, os intelectuais da economia solidária realizam uma releitura marxista do

1 Pesquisa financiada pelo CNPq.

2 Enquanto os antigos intelectuais defendiam o cooperativismo como uma doutrina social e econômica com características morais (Gide, 1937), os atuais o defendem como noção organizativa dentro do sistema capitalista (Pinho, 1982; Beloque, 2000). Para melhor examinar as noções doutrinária, organizativa e a de lugar (a última explicada neste artigo) e suas transformações, ver: Ide (2004). 
cooperativismo. Como característica comum, ambas as tendências tomam como referência principal, além dos socialistas utópicos, a experiência cooperativista de Rochdale (Inglaterra), fundada em 1844 por 28 tecelões.

Posto que a questão sobre o modo de inserção social das cooperativas entre a tendência tradicionalista já foi discutida pelos seus intelectuais e dirigentes na década de 1980, conforme exposto adiante, o presente artigo propõe-se a examinar as possibilidades de efetivação cotidiana das cooperativas. Esse exame vai em direção à pergunta feita por Paul Singer (1998) sobre os motivos que levam as cooperativas a degenerarem, isto é, a perderem seu caráter autogestionário.

Para responder essa questão, utilizou-se de alguns pressupostos construcionistas tais como desenvolvidos por Peter Spink e Mary Jane Spink. Tais pressupostos concebem o conhecimento como sendo intersubjetivo e histórico, negando, dessa forma, toda a essência $a$ priori.

A partir dessa postura frente ao tema da pesquisa foram utilizadas três noções construcionistas. A primeira é a noção de campo-tema. Segundo Peter Spink (2003), ao conceber que o campo a ser investigado não é uma realidade independente do pesquisador, mas um produto social, o campo não é um lugar específico, mas a situação de um assunto, os múltiplos sítios que o produz e que o fazem circular. $\mathrm{O}$ processo de investigação constitui-se, portanto, em um processo negociado entre o pesquisador e os lugares que irá visitar ou, ainda, entre o pesquisador e a situação dos assuntos que ele irá investigar. Vista a constatação de que o campo-tema do cooperativismo é marcado por vários disputas entre as tendências, a investigação procurou se situar nas regiões nas quais os debates se fizeram presentes, no caso, as interfaces existentes entre as tendências tradicionalistas e as da economia solidária.

A segunda é a de contexto de diálogos. Segundo Mary Jane Spink, o contexto dos sentidos institui o diálogo contínuo entre sentidos novos e antigos, considerando que tais sentidos não são estáticos:

Mesmo os sentidos passados, decorrentes de diálogos travados há muitos séculos, não são estáveis; são sempre passíveis de renovação nos desenvolvimentos futuros do diálogo. Em qualquer momento, essas massas de sentidos contextuais esquecidas podem ser recapituladas e revigoradas assumindo outras formas (em outros contextos) (Spink \& Medrado, 1999, p. 49).

No contexto deste artigo examinar-se-á como as noções cooperativistas, especialmente a doutrinária, toma formas bastante diferenciadas conforme os períodos analisado: (a) meados do século XIX, (b) início do século XX, ambos na Europa, e (b) final do século XX e início do XXI no Brasil.

A terceira noção, vinculada à anterior, é a do tempo. Noção central da história, Mary Jane Spink divide-o em três esferas. A primeira esfera é a do tempo longo, tempo histórico no qual podemos apreender os repertórios disponíveis que serão moldados pelas contingências sociais de uma dada época; a segunda é a do tempo vivido, o tempo no qual ocorrem os processos de ressignificação dos conteúdos históricos no curso da experiência pessoal; e, por último, o tempo curto, que é o tempo da interanimação dialógica face-a-face ${ }^{3}$ (Spink \& Medrado, 1999, p. 49).

3 Salienta-se, acerca do tempo vivido, que essa esfera não foi investigada, posto o caminho traçado por esta pesquisa, cujo método utilizou-se de documentos públicos e livros. Especificamente em relação ao tempo curto, ele foi representado pelas publicações atuais dos dirigentes e intelectuais envolvidos com o cooperativismo, especificamente em São Paulo, capital, e um jornal de grande circulação, a Folha de S.Paulo. 
Além destes contextos de diálogos, examinou-se outra noção: o cooperativismo como lugar. Essa noção parece estar implicada na efetivação cotidiana de uma cooperativa, como visto na obra do ativista cooperativista inglês George Jacob Holyoake (1857/1907). A partir dessa suposição, este artigo propõe examinar com detalhes suas implicações na gestão cotidiana das cooperativas.

Com o objetivo acima enunciado e visando examinar de que maneira os contextos de sentidos acerca do cooperativismo se transformam de acordo com os tempos, o presente artigo está organizado em três partes:

A primeira examina, tomando como referência o tempo longo, as origens em separado do cooperativismo e do marxismo, quando ambas eram doutrinas econômicas e sociais rivais. No tempo curto, expõe a leitura cooperativista feita pelo marxismo como o proposto por Paul Singer e a leitura marxista feita por cooperativistas da chamada tendência tradicionalista, sucessores dos antigos intelectuais da ACI no Brasil.

A segunda parte examina algumas pesquisas realizadas por psicólogos sociais acerca da participação dos chamados agentes externos nas cooperativas, que podem atuar tanto nas Incubadoras Tecnológicas de Cooperativas Populares (ITCPs), quanto em entidades representativas do cooperativismo, como a Organização das Cooperativas do Estado de São Paulo (OCESP). Característica comum é a menção de que ela deva ser minimizada em favor da continuidade dos empreendimentos.

A terceira parte propõe a noção de lugar para a auto-organização do coletivo de trabalhadores. Noção examinada ou inferida nos três períodos analisados, pelo que consta na bibliografia revisada, dir-se-ia ser primordial na auto-organização do coletivo de trabalhadores na forma de cooperativas.

\section{O cooperativismo e o marxismo: teorias em disputa ou complementares?}

Como examinado na bibliografia, as opiniões de Marx e Engels em relação ao cooperativismo podem ser tanto favoráveis, como em Do socialismo utópico ao socialismo científico, quanto contrárias, como em O Manifesto comunista. Seria por isso talvez que no tempo curto (nas universidades paulistanas), a teoria de Marx, denominador comum entre algumas leituras tradicionalista e da economia solidária, tem funções tão distintas como a de defender o cooperativismo incluso no mercado auto-regulado capitalista (Beloque, 2000), quanto a de ser um elemento, dentre outros, da revolução social socialista como apregoada por Paul Singer (1998).

O último autor, considerado um dos expoentes intelectuais da economia solidária no Brasil, defende a noção do cooperativismo como práxis revolucionária (Singer, 1998). Assim, no tempo curto (a atualidade) a noção doutrinária mantém-se preservada na forma de proposições de um sistema econômico e social a serem efetivadas de acordo com a transformação cultural do proletariado.

Essa transformação poderá ocorrer, segundo ele, através da educação cooperativa ou da aliança do movimento com alguns setores da sociedade, como os sindicatos. Essa concepção é distinta do marxismo-stalinista da antiga União Soviética (sistema político existente nesse país até 1992), que errou ao conceber que a revolução poderia se efetivar segundo um único golpe de cima para baixo. 
Para Singer, esse tipo de revolução, definida como revolução política, ofuscou o conceito de revolução social, que se refere ao processo multissecular de passagem de uma formação social para outra. Esse processo está se constituindo através de uma longa transformação cultural, onde houve momentos históricos nos quais o proletariado atuou como protagonista.

Dentro da chamada revolução social socialista, o cooperativismo, assim como a democracia e o sindicato, são definidos como implantes socialistas que o movimento social conseguiu colocar nos interstícios do sistema capitalista de produção ao longo dos dois últimos séculos. Como processo cultural, a revolução social socialista, dentro do regime democrático, ainda não se tornou hegemônico requerendo a aliança com outros setores da sociedade.

Todavia, a leitura do cooperativismo pelo marxismo como apregoada por Singer (1998) nem sempre existiu: conforme examinado no tempo longo, o cooperativismo constituía uma doutrina social, política e econômica à parte e rivalizava com o marxismo (Gide, 1937; Mladenatz, 1944). Alguns intelectuais ligados à ACI, seguidores da chamada Escola de $\mathrm{Nimes}^{4}$, pretendiam, tal como os marxistas, fazer uma revolução a partir das cooperativas de consumo, a fim de se fundar a República Cooperativa (Pinho, 1982, p. 36).

O cooperativismo como doutrina econômica e social elaborada pelos antigos intelectuais da ACI defendia a tese de que os distintos interesses econômicos e políticos numa sociedade de produtores tornavam a sociedade dividida. Para eles, o cidadão, como produtor, é antes um servidor ou escravo da coletividade. Conforme um dos dirigente da Aliança da época, Hans Müller:

Ao igual, que dentro da organização política democrática do Estado e da comunidade, o cidadão é quem forma a unidade que governa e representa em sua totalidade a vontade soberana da nação, assim mesmo, na organização econômica democrática da cooperativa local e da união nacional, o direito à decisão definitiva cai também na totalidade dos consumidores. Nesse Estado Cooperativo cada quem é, em sua qualidade de consumidor, um cidadão livre e soberano, mas como produtor é somente um servidor da coletividade (citado por Mladenatz, 1944, p. 120).

A revolução como apregoada pelos dirigentes da Aliança Cooperativa Internacional partiria das cooperativas de consumo que, após obterem fundos suficientes, organizariam ou comprariam cooperativas de produção. Após essa segunda fase, seriam adquiridas cooperativas agrícolas, formando um conjunto orgânico, pois era um objetivo comum da época unir os meios urbano e rural (Mladenatz, 1944). Porém, como registrado pela historiador Mladenatz, essa revolução não alcançou a terceira fase em decorrência da oposição do movimento sindical da época, que requeria a possibilidade de ocupar postos chaves nas cooperativas. Uma outra razão, sem dúvida, foi a consolidação do mercado autoregulado que esvaziou as cooperativas de consumo dos seus cooperados como se pode inferir pela leitura mais recente de Paul Singer (1998).

No tempo curto, a leitura marxista do cooperativismo da tendência tradicionalista pretere a República Cooperativa em favor de um cooperativismo moldado segundo técnicas organizativas capitalistas. Assim, Leslie Beloque (2000) defende um cooperativismo incluso no mercado auto-regulado, mencionando que, quando Marx cita a cooperação (e não o cooperativismo), fala de cooperação dentro da fábrica; fora dela o mercado auto-regulado inevitavelmente institui suas regras. A título de exemplo, a autora cita a transformação de

4 Salienta-se que a Aliança Cooperativa Internacional era formada por vários agrupamentos sendo os seguidores da Escola de Nimes (de origem francesa) um deles. Havia desde os que defendiam as cooperativas de produção, como os socialistas cristãos, até os que defendiam o cooperativismo agrícola, como os dirigentes húngaros. 
uma cooperativa de Minas Gerais, conhecida pela Marca Itambé em Sociedade Anônima (Beloque, 2000, p. 126).

Nessa mesma linha de argumentação, Benevides Pinho (1982, pp. 56-59) - expoente intelectual da tendência tradicionalista em São Paulo -, alinhando-se à leitura de Rosa de Luxemburgo, cita que Marx concebia as cooperativas como sendo apenas soluções paliativas, uma vez que constituíam uma contradição dentro de uma contradição. A autora salienta, porém, que ele as percebia como forma de transição para o socialismo.

Assim, se no tempo longo, a literatura aponta o cooperativismo e marxismo como doutrinas econômicas e sociais em disputa (Gide, 1937; Mladenatz, 1944), no tempo curto, a bibliografia analisada, ou (a) utiliza o cooperativismo para justificar o marxismo como noção doutrinária, na forma de um sistema econômico e político como a economia solidária faz (Singer, 1998; Haddad, 2002), ou (b) utiliza do marxismo para justificar o cooperativismo como noção organizativa, inserida no mercado auto-regulado, como fazem os tradicionalistas (Pinho, 1982; Beloque, 2000).

Essas leituras, a tradicionalista e a da economia solidária, devem ser compreendidas num contexto histórico mais amplo, posto que, conforme mencionam Bestor e Gurney, o cooperativismo, o comunismo e o socialismo constituem terrenos intercambiáveis ao longo dos dois últimos séculos:

Até cerca de 1848, cooperação, comunismo e socialismo eram palavras intercambiáveis e carregavam uma ênfase anticapitalista semelhante. Esse conceitos têm sido campos de batalha complexas e prolongadas durante os dois últimos séculos (Bestor \& Gurney citados por Bottomore \& Outwaite, 1996, p. 485).

No tempo curto, supor-se-ia que as diferentes leituras derivam das opiniões cambiantes de Marx e Engels acerca do tema ${ }^{5}$. Elas demonstram de que maneira sentidos passados podem ser recapitulados e transformados em outras formas diferentes, em outras épocas, constituindo o que Spink e Medrado (1999) denominam de contextos de diálogos (p. 49).

Além disso, as interações entre tais tendências são marcadas por alguns conflitos, expressos sob o debate acerca do verdadeiro cooperativismo ou do cooperativismo autêntico, isto é, sobre a legitimidade do movimento em questão frente a sociedade. Essa interação junto com a presença de outros protagonistas tais como o Ministério Público do Trabalho e das "coopergatos", presentes de forma maciça, vem corroborar a menção de Peter Spink de que o campo-tema é antes um tumulto conflituoso, com verdades parciais em disputa (Spink, 2003).

Teorias complementares ou em disputa, salienta-se por último que apenas no marxismo da economia solidária dar-se-á o debate sobre as cooperativas geridas de baixo para cima, denominadas por ela de autogestionárias.

5 Acerca das distintas exposições salienta-se de que apenas a leitura minuciosa da obra de Marx e dos socialistas utópicos poderia fornecer maior número de argumentos para melhor dimensionar a questão no tempo longo. 


\title{
O cooperativismo e a autogestão
}

Dentre as duas tendências mencionadas acima, sendo a economia solidária a que se preocupa com as cooperativas coletivas, traz-se para a discussão a questão que lhe é central, a autogestão. Esse conceito, conforme exposto por Paul Singer, é o elemento que diferencia a economia solidária dos tradicionalistas. Segue abaixo um resumo do desenvolvimento conceitual da autogestão pelo autor, contraposta à heterogestão de uma empresa comum:

\begin{abstract}
$\mathrm{Na}$ empresa comum, as informações tendem ir de baixo para cima e as instruções de cima para baixo através dos níveis hierárquicos. A heterogestão, modelo administrativo desse tipo de empresa, localiza-se no meio da seguinte contradição: ela deve suscitar o máximo de cooperação entre seus empregados e colaboradores ao mesmo tempo que deve incentivar a competição sadia entre eles [...] De outro lado, numa empresa autogestionária, as informações tendem ir de cima para baixo e as instruções e ordens de baixo para cima. Diferentemente da heterogestão, os níveis mais altos são delegados pelos mais baixos e são responsáveis pelos mesmos. Disso decorre que todos os sócios, os trabalhadores de uma cooperativa, devem estar informados do que ocorre no empreendimento, exigindo deles uma atitude inquiridora e proativa frente as decisões a serem tomadas nas Assembléias e pelo grupo dirigente (Ide, 2004, p. 118).
\end{abstract}

Nesse sentido, cabe acrescentar que além da versão de Paul Singer, a psicóloga social Cedeño (1999) acrescenta outras categorias: autogestão estatal, liberal, libertária, microcomunitária, sem patrão e agente externo. Tais categorias são dinâmicas, isto é, uma organização pode transitar de uma para outra de acordo com as circunstâncias como examinado na associação comunitária por ela investigada, Mãos Unidas, do Jardim dos Pássaros.

Entre essas categorias, a última versão, a do agente externo, é a que mais interessa aqui, pois no campo-tema do cooperativismo pode se conformar, ou como uma entidade representativa como a OCESP (Organização das Cooperativas do Estado de São Paulo, da tendência tradicionalista), ou uma incubadora universitária como a ITCP (Incubadora Tecnológica de Cooperativas Populares, da tendência da economia solidária).

Proveniente da prática da psicologia comunitária dos países do Caribe, o "agente externo entra com a missão de suscitar a autogestão no grupo, através da tomada de consciência do mesmo sobre sua situação, e da eleição e efetivação de vias de ação" (Cedeño, 1999, p. 175). Em relação a ele, a autora faz a seguinte pergunta: pode se ensinar a autogestão para um agrupamento de pessoas?

Cedeño, partindo da noção de que a autogestão ocorre a partir dos saberes autóctones, aponta que a participação do agente externo deve ser minimizada, visto que pode esconder sutilmente relações hierárquicas entre ele e o agrupamento que pretende se tornar autogerido:

No caso da autogestão no âmbito comunitário e fabril, as relações dos protagonistas com os assessores têm uma grande possibilidade de estar marcadas por diferenças de classe que, aunadas ao histórico esclarecedor da esquerda - aparentemente herdada de Lenin e à separação entre os que têm e os que não têm, os que estudaram (ou sabem) e os que não o fizeram (não sabem), requerem de muita atenção e autocrítica por parte de todos os envolvidos para detectar e superar relações sutil ou explicitamente hierárquicas (Cedeño, 1999, p. 176).

No âmbito das cooperativas agrícolas (patronais), onde se supõe que a autogestão é preterida, os psicólogos sociais Albuquerque e Mascareño também apontam que a participação do agente externo deve ser minimizada. Eles observam que é o empenho pessoal 
de cada cooperado, na forma de trabalho ou na aplicação de bens materiais, o mais importante determinante no comprometimento do cooperado a longo prazo, sem o qual poderá implicar a desestruturação da cooperativa na primeira dificuldade enfrentada (Albuquerque \& Mascareño, 1999, p. 33).

Os apontamentos de Cedeño (1999) e de Albuquerque e Mascareño (1999) acerca da necessidade de minimização da participação do agente externo fornecem o argumento necessário para a introdução da temática do cooperativismo como lugar, noção existente nos diferentes períodos analisados. Como veremos adiante, no tempo curto, o exame do lugar demonstra a necessidade de se considerar os saberes e vínculos sociais aí constituídos na efetivação do empreendimento.

\section{O cooperativismo como lugar}

Em favor das cooperativas formadas a partir do coletivo, traz-se ao debate as idéias de alguns autores como Holyoake (1857/1907), Karl Polanyi (1980), Peter Spink (2000) e Sato e Esteves (2002), envolvidos direta e indiretamente com a temática do lugar.

A temática do lugar na psicologia social tem sido desenvolvida por Peter Spink (2000) e seu eixo de atenção é o âmbito das políticas públicas. Em uma série de reuniões onde participavam 146 pessoas envolvidas com a questão das políticas públicas (dirigentes de ongs, militantes, representantes de governo municipais e estaduais entre outros), discutiu-se a seguinte questão: "haveria um espaço de ação para combate a pobreza entre as macro políticas nacionais e as micro ações de solidariedade desenvolvidas a partir da sociedade civil?". As respostas podem ser assim sintetizadas:

...a cara da gente, uma arena de demandas, conflitos e reinvindicações para a melhoria na qualidade da vida; ... denso, é a vida das pessoas em espaço e tempo que dependendo das circunstâncias pode ser o bairro, o município ou a região; ...é onde se enraízam as experiências; territorialidade e identidade - o lugar, as raízes históricas e culturais; ...o ponto de partida para a intersetorialidade; ...uma nova concepção do local visto como lugar, onde a lógica da proximidade, do encontro e do confronto é possível; ...que não é dado, mas se define e se redefine a partir das ações, remetendo a um contexto de relações que não é somente local; ...o motor de arranque no enfrentamento da pobreza e a base da discussão sobre desenvolvimento; ...um processo gradual de aproveitamento de oportunidades, de aprendizagem e de luta (Spink, 2000, pp. 4-5).

Para o autor, a discussão dessa temática justifica-se na medida que há a ausência de um termo de médio alcance no que se refere ao espaço existente entre o indivíduo e o Estado sem o qual, conforme Hewstone, Strobe, Codol e Stephenson (citados por Spink, 2000, p. 14) a discussão entre um e outro se torna de caráter meramente ideológico.

Argumentando a favor do lugar como noção de médio alcance, essa temática pode conformar-se como um lugar povoado, cujo caráter intersubjetivo dá o seu sentido de pertencimento, onde se dão as lutas para a inclusão no mundo vivido (Habermas citado por Spink, 2000, p. 5). Ainda, no lugar, entrecruzam-se o nacional e o internacional, o particular e o universal, constituindo assim uma unidade analítica que não privilegia um centro, como outro termo, o local, que implica necessariamente o que lhe é mais amplo.

Ao adotar uma postura sócio-histórica, mas não se reduzindo a ela, o autor deriva a sociedade civil a partir da noção de lugar, contexto amplo e marcado por disputas. Há, segundo ele, três versões circulantes sobre a sociedade civil: (a) a que se inspira no liberalismo escocês, (b) a marxista e a (c) que se automobiliza. A primeira se caracteriza por 
ser o protesto dos incluídos, seus integrantes consideravam-se o contrapeso necessário ao Estado. A segunda, a marxista, envolve a questão da luta contra o poder do Estado num jogo onde a soma é sempre zero. A terceira, a que se automobiliza, caracteriza-se pelas associações, famílias ou esferas públicas que, regulamentadas pela lei, ocupam os espaços da sociedade civil.

Como examinamos nas reportagens da Folha de S. Paulo no período entre 1994 e 2002, as iniciativas cooperativistas podem conformar-se segundo essas três versões da sociedade civil. O cooperativismo, aclamado como solução para a crise do desemprego por políticos e cientistas das mais diferenciadas tendências políticas (desde Paulo Maluf até Aluízio Mercadante), configura-se como o protesto dos incluídos. A iniciativa da economia solidária conforma-se na segunda versão (como visto anteriormente).

Em número reduzido, foram encontradas reportagens sobre agrupamentos de mães, perueiros e catadores de papéis que, após se auto-organizarem (como as primeiras) ou entrarem em confronto com o governo municipal (como os últimos), conseguiram se firmar economicamente. ${ }^{6}$

Nessa última versão de sociedade civil podem ser encontradas as cooperativas que mais se aproximam do ideal autogestionário de Singer. Salienta-se, porém, como afirmam Cedeño (1999) e Évora (1996), que essas cooperativas foram criadas a partir de agrupamentos já formados, na sua luta diária pela sobrevivência. A efetivação das cooperativas, portanto, foi o efeito de uma condição já estabelecida, denominada anteriormente de lugar.

Lugares nos quais cooperativas são criadas, efeito da ação conjunta de pessoas, não são exclusividade de uma determinada época. Conforme examinada na pesquisa no campotema, a condição de lugar no cooperativismo pode ser constatada em outros períodos, refletindo, como Peter Spink menciona, que nas práticas institucionais e cotidianas, o presente e passado estão implicados (Spink, 2003, p. 30).

Dessa forma, curiosamente, não foram as reportagens da Folha de S. Paulo que mais freqüentemente mencionaram a noção de lugar durante a pesquisa no campo-tema. A noção de lugar como espaço de luta e de pertencimento, também pode ser encontrado na mais antiga publicação por nós encontrada, Self-help by the people - the history of Rochdale pioneers, escrito originalmente em 1857 por George Jacob Holyoake.

Holyoake era um homem que participava ativamente do movimento social de sua época. Filho de engenheiro, ele iniciou sua vida política no movimento inglês, quando entrou para a Liga de Reforma de Birmingham em 1831. Teve participação nas campanhas para redução de impostos de jornais e na reforma do sistema eleitoral. Foi redator, livreiro e editor, sendo o último preso pelo crime de blasfêmia na Inglaterra. Escreveu vários artigos de jornal, panfletos e livros relacionados ao cooperativismo, tendo aí posição de destaque: foi um dos que organizaram o primeiro Congresso Cooperativo em 1869, editou os relatórios do terceiro ao quinto e presidiu o sétimo. Como escritor, sua função era antes a de inspirar para ação do que narrar fatos.

Em relação à iniciativa de Rochdale, o autor menciona que alguns operários se reuniram a fim de discutir como poderiam melhorar suas condições de vida após uma greve fracassada. Alguns propuseram a entrada no movimento cartista, cuja última greve geral

6 É interessante, contudo, perceber como uma iniciativa da sociedade civil é cooptada pela sociedade política e pela sociedade econômica. Um exemplo disso foram os perueiros, que depois de conseguirem abrir seu espaço de atuação num processo bastante conflituoso com a prefeitura, foram posteriormente arregimentados por ela, a fim de atuarem no chamado subsistemas locais ou os ramais secundários das linhas de ônibus. Se antes a organização dos serviços era de sua responsabilidade, após a regulamentação ficaram subordinados ao poder público, seguindo suas padronizações técnicas. Outro exemplo, dessa vez referente à cooptação pelas empresas da construção civil, foram as cooperativas habitacionais. Originalmente criadas pelos sindicatos dos metalúrgicos do ABC no final da década de 1970, em meados da década de 1990 elas começam a se proliferar, pois as construtoras, percebendo seu grande sucesso nas vendas, começam a criá-las para si mesmas. 
havia ocorrido quatro anos antes, outros sugeriam a emigração para os Estados Unidos. Uns seguiram um ou outro caminho, porém a medida que teve consenso foi a criação de uma cooperativa. Cada um dos vinte e oito tecelões semanalmente depositavam a modesta quantia de dois pences para fundá-la. Aproximadamente depois de um ano, inauguraram a cooperativa de Rochdale em Toad Lane.

Por vezes, o ativista inglês utiliza da ironia para descrever a relação entre os cooperados e os habitantes da região. Após abrirem timidamente suas portas, alguns meninos trabalhadores, os doffers, que trocavam as bobinas de fios vazias por outras cheias, riam da modesta loja. Escarneciam dos parcos arranjos de aveia e manteiga, ventilando suas opiniões em voz alta, além de que urinavam com impertinência ridícula nos cantos externos da loja. Entretanto, após duas gerações, crescendo bem alimentados e bem vestidos por artigos da cooperativa, muitos dos doffers estavam a ela integrados.

Com o passar dos anos, a cooperativa transformou-se em um ponto de encontro social no vilarejo. Nos sábados a noite, muitos operários humildes, que antes não teriam dinheiro suficiente, iam para lá comprar seus mantimentos no seu próprio mercado. Por essa hora, não apenas a loja funcionava, como também a sapataria, o açougue, a biblioteca, com cerca de duzentos livros, um produto caro na época. Com os altos excedentes da cooperativa, a abundância tornava-se comum entre eles:

Maridos que nunca souberam o que é não possuir dívidas e pobres esposas que, durante quarenta anos, nunca possuíram seis pences em seus bolsos, agora possuíam dinheiro suficiente para construir suas casas e iam toda semana para seu próprio mercado com moedas tinindo em seus bolsos (Holyoake, 1857/1907, p. 41).

Holyoake especula que a cooperativa não teria êxito em cidades como Londres ou Liverpool onde a vida agitada com suas inúmeras atrações culturais afastariam as pessoas da ação em conjunto. Do contrário, se existiam pessoas dispostas a agir em Rochdale, nada as impediriam (Holyoake, 1857/1907, p. 61).

A noção de lugar pode ser inferida mais tardiamente na narrativa de Paul Singer (1998) acerca do declínio das cooperativas de consumo vinculadas à Aliança Cooperativa Internacional (ACI), ocorrido a partir do início do século XX. Conforme o autor, a popularização do automóvel que permitia ao cooperado realizar suas compras em estabelecimentos mais longínquos e a invenção da empresa capitalista de venda a varejo, o supermercado, cujos produtos se auto-vendiam através de suas embalagens, tornaram mais impessoais as relações entre os cooperados.

Aliás, a própria expansão do mercado auto-regulado ao longo do tempo, testemunhada pelos pioneiros no século XIX, nas palavras de Peter Spink, "deslugareificou" as regiões onde se tornou hegemônico.

Essa noção pode ser encontrado com maiores detalhes no livro de Karl Polanyi, citado por Paul Singer, A grande transformação (1980), no qual o autor através de estudos antropológicos, econômicos e históricos defende a idéia de que a tese do mercado autoregulado é a utopia liberal que deu certo.

Segundo Polanyi, após a derrota de Napoleão em 1815, o mercado auto-regulado foi se constituindo como uma matriz comum, que regula não apenas o padrão-ouro, mas também os Estados liberais, o mercado interno de cada país e o equilíbrio de poder entre eles. Porém, à medida que o mercado auto-regulado se expandia pelo mundo, Polanyi constata que a noção de lucro substituiu a de sobrevivência e a noção de mercadoria a de trabalho humano.

Tais substituições, cujo papel legitimador coube aos pensadores liberais, deslugareificou os lugares, onde os saberes autóctones eram hegemônicos, como pode ser inferido a partir do declínio das cooperativas de consumo na Europa. Entende-se por 
deslugareificarção, portanto, a destruição gradativa das formas coletivas locais de organização em favor das técnicas de produção capitalista.

A noção de Polanyi de que mercado auto-regulado e vínculos sociais se excluem mutuamente, pode ser examinada no texto de Sato e Esteves (2002), Autogestão: possibilidades e ambigüidades de um processo organizativo peculiar. Segue abaixo, um resumo elaborado a partir de algumas ocasiões-problemas enfrentadas pelas cooperativas. Como expostas pelos autores, elas bem demonstram de que maneira, no tempo curto, as cooperativas vinculadas à economia solidária estão interagindo com o mercado auto-regulado:

Uma cooperativa industrial reinveste constantemente as sobras líqüidas na cooperativa em vista do seu crescimento. Esse investimento amplia o capital social da cooperativa, mas fica indivisível aos sócios cooperados. Estabelece-se uma situação contraditória entre a autogestão do grupo que decide investir as sobras no capital social da empresa e a heterogestão jurídica do grupo que cria um patrimônio não divisível individualmente; $\mathrm{Na}$ assembléia geral ocorre um impasse: devem ajustar o patrimônio do capital social da cooperativa ou mantê-lo como está? Caso optem pela primeira opção, efetivam o objetivo acima, aumentando o valor da cota-parte dos cooperados. Mas não apenas aumentam o valor deles, como também dos que acaso desejem integrar na cooperativa, dificultando o acesso;

Os cooperados decidem pela primeira opção e aumentam periodicamente o capital social da cooperativa e as cotas-partes de cada um. Assim, ano após ano, cresce o valor que uma pessoa deve possuir a fim de entrar na cooperativa. Outro impasse ocorre quando um grande contrato é fechado necessitando, assim, arregimentar um grande número de pessoas. A dúvida que surge é o que fazer? Diminuir o valor da cota-parte para possibilitar a entrada de outros cooperados? Essa medida levaria para a primeira questão, pois a medida diminuiria o investimento no capital social. Do contrário, não diminuindo o valor da cota-parte, a opção seria contratar empregados; porém a cooperativa deixaria de ser autogestionária;

Outra cooperativa industrial decide comprar maquinário para aumentar a produção de um determinado artigo com alta probabilidade de retorno financeiro. Consegue emprestar dinheiro de uma agência de crédito que, por sua vez, também empresta para outras empresas privadas pelas mesmas razões. Quando a produção é implementada com as novas máquinas surge uma questão: as concorrentes dispõem de um produto similar com um custo menor, haja visto que o salário bruto pago pelas empresas é cerca de 30\% menor em relação às retiradas da cooperativa. Em relação a esse problema a única solução da cooperativa é a diminuição da retirada. Percebe-se, outra vez, a heterogestão do mercado sobre a autogestão da cooperativa;

Outra cooperativa industrial, oriunda de uma empresa capitalista após processo falimentar, possui uma organização de cargos composta por várias faixas de remuneração. Como o plano de cargos e remuneração é transparente, como convém a uma cooperativa, e as decisões tomadas por votações em assembléia, os novatos pedem que a remuneração seja equânime. $\mathrm{O}$ impasse levantado pelos últimos é este: se isto é uma cooperativa, em que existe igualdade política não deveria existir também igualdade econômica? Os veteranos são contrários ao aumento, pois entendem que alguns trabalhos são mais importantes e exigem maiores responsabilidades que outros, além de que, os maiores salários são justificados na medida que mantém profissionais mais qualificados.

Segundo os autores frente a essas situações-problemas, os cooperados chegam a soluções surpreendentes. Está claro que esse resultado não seria alcançado se antes a cooperativa não se conformasse num lugar, ainda que eles utilizem o termo grupo para apontar a historicidade de agrupamentos de trabalhadores que se reuniram para efetivar o empreendimento. 
Assim, em favor dos saberes dos próprios cooperados e em detrimento dos saberes técnicos e burocráticos, as cooperativas tornaram-se lugares onde as soluções, citadas abaixo, são debatidas não apenas nos espaços formais, como reuniões e assembléias, mas também nos informais, como os encontros nas horas de folga e os cafés:

Existem exemplos de cooperativas em que as retiradas se dão em função das necessidades dos sócios, mensuradas pelas condições socioeconômicas de suas famílias; outras permitem licenças remuneradas quando não há trabalho para todos; outros subvertem o mercado oferecendo serviços e produtos a preços inferiores aos comumentes praticados; outras criam gigantescos sistemas de seguridade social para que sócios, em situações de dificuldades, tenham todo apoio possível da cooperativa; outras organizam os horários de trabalho em função das demais atividades dos cooperados; outras promovem festas para agregar e conquistar os familiares e conhecidos dos cooperados para o projeto da cooperativa; outras lutam por subsídios para sua atuação diante de parcelas da sociedade excluídas da possibilidade de pagar por seus serviços, defendem o direito ao trabalho de atender toda a população e assim por diante (Sato \& Esteves, 2002, pp. 37-38).

A noção de que se deva privilegiar os processos organizativos mais relacionais, vinculados à cultura local nas cooperativas e de caráter menos burocrático, a fim de que elas se tornem autogestionárias pode ser também percebida na pesquisa de Évora (1996), na Ilha de Santiago, Cabo Verde. Segundo a autora, deve-se considerar a diferença entre a concepção oficial e o saber local, pois o último mostrou ser mais determinante na efetivação dos empreendimentos:

A permanência de formas anteriores de comportamento social evidenciam a influência de fatores de ordem cultural, do sistemas de valores e da atividade do sujeito que se mostraram muito mais determinantes das condutas do que as pressões da nova situação e as condições objetivas pela inserção de instrumentos associados a uma proposta de transformação do meio sócio-econômico e de mudança social. Ao invés da prática do cooperativismo modificar as formas anteriores dos indivíduos se organizarem para garantir a sobrevivência, verifica-se que a proposta revolucionária é que se integra ao sistema anterior de representações sem que estas se modifiquem nos seus elementos centrais (p. 131, itálicos nossos).

Seguindo a linha de argumentação construída, justifica-se, pois, a introdução da noção de lugar na efetivação cotidiana das cooperativas, posto que seja uma das condições determinantes para que o coletivo de trabalhadores se auto-organize na forma de cooperativas, contribuindo assim para que se cumpra a meta autogestionária de Paul Singer (1998).

Acreditamos ser válida esta introdução, pois, apesar da relação de exclusão entre o mercado auto-regulado e de lugar como exposto por Karl Polanyi (1980) e Sato e Esteves (2000), as tendências atuais, a tradicionalista e a economia solidária, não questionam a centralidade do mercado auto-regulado. Assim, se a economia solidária defende a criação de um mercado paralelo, a fim de proteger os empreendimentos nascentes do mercado autoregulado, os tradicionalistas chegam mesmo a apontar a necessidade de inserção do cooperativismo no mercado auto-regulado. Essa posição tradicionalista está implícita, por exemplo, nas declarações de alguns congressos internacionais. O Congresso Nacional Cooperativo organizado pelo Conacoop (Conselho Nacional de Cooperativas) de Costa Rica, realizado em 1981, declarou:

Que se deve superar a colocação rochdaleana romântica da cooperativa como instrumento de defesa dos mais débeis atores econômicos, posição que conduz a uma ação marginal e limitada [...] Que, em conseqüência, a cooperativa deve atuar em 
direção ao exterior, como qualquer outra empresa econômica, respeitando internamente os princípios cooperativistas segundo sua concepção atual (Pinho, 1982, p. 89).

Nas declarações do Primeiro Congresso Colombo-Venezuelano de Integração Cooperativa, ocorrido em 1978, encontra-se a seguinte afirmação:

Em todos os cursos de cooperativismo não se faz outra coisa senão exaltar o exemplo de Rochdale como algo digno de imitação. Mas não puderam dizer como terminou a experiência dos Pioneiros. Não acabaram eles exercendo exploração idêntica à das sociedades capitalistas e cartéis por volta de 1862? (Pinho, 1982, p. 90).

Respondendo à questão colocada no início deste artigo, a que interroga sobre os motivos que levam uma cooperativa a degenerar-se ou não, deve se deixar apontado a necessária desnaturalização do mercado auto-regulado em favor dos processos organizativos que privilegiem os vínculos sociais do lugar, como apontam Sato e Esteves (2002), pois as relações hierárquicas e individualizantes do mercado auto-regulado acabam por se impor no cotidiano das cooperativas, já que a idéia de que "fatores de ordem cultural, do sistemas de valores e da atividade do sujeito são mais determinantes que a proposta de transformação social" (Évora, 1996, p. 131), certamente é válida para pessoas que sempre trabalharam em empresas comuns.

\section{Comentários finais}

A partir da linha de argumentação construída, a noção do cooperativismo como lugar ergue-se como primordial na efetivação cotidiana ou autogestionária de uma cooperativa. A seu favor, pontua-se a necessária desnaturalização do mercado auto-regulado, a fim de que as relações hierárquicas e individualizantes nelas não se repitam. Essa constatação vem ao encontro de duas questões: não deveriam os princípios rochdaleanos - elementos que identificam o movimento frente a sociedade - ser também relativizados? Mas ao se relativizarem os princípios rochdaleanos, o cooperativismo não deixaria de existir?

Vistas essas questões doutrinárias, não se poderia deixar de apontar que há uma diferença em como são expostas a experiência cooperativista de Rochdale (meados do século XIX) e a experiência da Aliança Cooperativa Internacional (início do século XX): se em Rochdale, como relatado por Holyoake (1857/1907), os princípios eram produtos de um consenso coletivo (ou do lugar), na experiência da ACI, eles eram expostos como imperativos categóricos (deve ser). Assim, poder-se-ia especular se o consenso amplo e coletivo em Rochdale foi um decisivo elemento no êxito do empreendimento.

Assim, privilegiando ainda a noção do lugar, ir-se-ia mais adiante nas questões acima: ao conceber o cooperativismo de maneira plástica - respeitada a conclusão de Évora (1996) de que o saber acerca do cooperativismo ancora num saber anterior, autóctone - ele não deixaria de existir na forma de princípios morais (ou organizativos) cristalizados para serem utilizados, como mencionado, de maneira plástica?

Salienta-se novamente que os princípios de Rochdale, segundo Holyoake (1857/1907), foram efeito do consenso, por vezes bastante tenso, entre os pioneiros no seu cotidiano. A resposta, porém, fica para pesquisas futuras. 


\section{Referências}

Albuquerque, F. J. B. \& Mascareño, R. P. (1999). Considerações não-ortodoxas sobre as cooperativas e o cooperativismo, Psicologia E⿱ Sociedade, 11 (2), 23-41.

Beloque, L. (2000). Contribuição para o estudo das sociedades cooperativas. Dissertação de Mestrado, Programa de Estudos Pós-Graduados em Administração, Pontifícia Universidade Católica de São Paulo, São Paulo.

Cedeño, A. L. (1999). Guia múltiplo da autogestão: um passeio por diferentes fios de análise. Dissertação de Mestrado, Programa de Estudos Pós-graduados em Psicologia Social, Pontifícia Universidade Católica de São Paulo, São Paulo.

Engels, F. (s. d.). Do socialismo utópico ao socialismo científico. São Paulo: Moraes.

Évora, I. M. A. (1996). As representações sociais da cooperativa: um estudo na ilha de Santiago, Cabo Verde. Dissertação de Mestrado, Instituto de Psicologia, Universidade de São Paulo, São Paulo.

Gide, C. (1937). O Programa cooperativista. Lisboa: Seara Nova.

Haddad, F. (2002). Sindicalismo, cooperativismo e política: as bases teóricas do socialismo republicano em Marx. São Paulo: Perseu Abramo.

Holyoake, G. J. (1907). Self-Help by the people - the history of Rochdale Pioneers. Londres: Swam Sonnenschein \& Co., Lim.; New York: Charles Scribners's Sons. (Originalmente publicado em 1857).

Ide, R. M. (2004). Cooperativismo ou cooperativismos: as intersecções entre noções doutrinárias e organizativas de uma palavra benquista. Dissertação de Mestrado, Programa de Estudos PósGraduados em Psicologia Social, Pontifícia Universidade Católica de São Paulo, São Paulo.

Marx, K. \& Engels, F. (s. d.) O manifesto comunista. Texto disponível na Internet: http://www.overmelho.org.br.

Mladenatz, G. (1944). Doctrinas cooperativas.

Outhwaite, W. \& Bottomore, T. (Org.). (1996). Dicionário do pensamento social do século XX. Rio de Janeiro: Zahar.

Pinho, D. B. (1982). O pensamento cooperativo e o cooperativismo brasileiro São Paulo: CNPq.

Polanyi, K. (1984). A grande transformação. Rio de Janeiro: Campus.

Sato, L. \& Esteves, E. (2002). Autogestão: possibilidades e ambigüidades de um processo organizativo peculiar. São Paulo: ADS-CUT.

Singer, P. (1998). Uma utopia militante: repensando o socialismo. São Paulo: Contexto.

Spink, M. J. P. \& Medrado, B. (1999). Produção de sentidos no cotidiano: uma abordagem teóricometodológica para análise das práticas discursivas. In M. J. P. Spink (Org.). Práticas discursivas e produção de sentidos no cotidiano (pp. 41-63). São Paulo: Brasiliense.

Spink, P. K. (2000). Um lugar para o lugar na psicologia. In Grupo de Trabalho: Cotidiano e Práticas Sociais. Serra Negra: VII Simpósio de Intercâmbio científico da ANPEPP.

Spink, P. K. (2003) Pesquisa de campo em psicologia social: uma perspectiva pós-construcionista. Psicologia EO Sociedade, 15(2), 18-42.

\section{Endereço para correspondência}

robmide.2007@ig.com.br

Recebido em: 01/03/2005

Pareceres enviados em: 03/08/2005

Revisão recebida em: 24/10/2005

Aprovado em: 01/11/2005 


\section{Cadernos de Psicologia Social do Trabalho}

\section{Pedido de assinatura e de exemplares avulsos}

Para fazer uma assinatura ou solicitar qualquer exemplar avulso, envie-nos a ficha abaixo preenchida e cheque nominal ao Instituto de Psicologia - USP. Por gentileza, escreva ou telefone para saber os valores atuais de cada exemplar ou da assinatura.

Centro de Psicologia Aplicada ao Trabalho

Av. Prof. Mello Moraes, 1721

Bloco D, sala 163

Cidade Universitária, São Paulo/ SP

05508-030

Endereço eletrônico: cpat@usp.br

\begin{tabular}{|l|l|c|c|}
\hline Quantidade & \multicolumn{1}{|c|}{ Pedido } & \multicolumn{1}{|c|}{ Valor $^{*}$} & \multicolumn{1}{|c|}{ Total } \\
\hline & volume 1 & esgotado & esgotado \\
\hline & volume 2 & & \\
\hline & volume 3/4 & & \\
\hline & volume 5 & & \\
\hline & volume 6 & & \\
\hline & $\begin{array}{l}\text { volume 7 } \\
\text { volume 8 }\end{array}$ & & \\
\hline & volume 9, número 1 & Total: R\$ \\
\hline & assinatura por dois anos (quatro exemplares) & & \\
\hline & & & \\
\hline
\end{tabular}

" Por favor, consultem-nos a respeito dos valores antes de fazer seus pedidos.

\begin{tabular}{|c|c|c|}
\hline Nome: & & \\
\hline Endereço: & & \\
\hline & & CEP: \\
\hline Cidade: & & Estado: \\
\hline Telefone: ( ) & E-mail: & \\
\hline Data: / / & Assinatura: & \\
\hline
\end{tabular}

